\title{
SEÇÃO: OLHARES GEOGRÁFICOS SOBRE MOÇAMBIQUE
}

\author{
SECTION: GEOGRAPHIC LOOKS AT MOZAMBIQUE
}

O objetivo dessa seção é socializar as reflexões realizadas por um conjunto de pesquisadores geógrafos acerca da geografia de Moçambique. Nessa perspectiva um conjunto de artigos que compõem esse número da revista Geouerj, foram produzidos a partir do projeto de mobilidade "Práticas sociais e saberes de mulheres e homens e a produção do território rural no Distrito de Marracuene em Moçambique: viabilidade das alternativas produtivas no mundo da sustentabilidade", coordenado pelo professor Edvaldo Cesar Moretti da Universidade Federal da Grande Dourados (UFGD)- Brasil e pela professora Ines Raimundo da Universidade Eduardo Mondlane (UEM)-Moçambique. O projeto foi financiado pela CAPES/AULP, através de edital de Mobilidade, aprovado no ano de 2013.

Deste conjunto de artigos, seis deles, são relatos de experiências vivenciados pelos membros do Projeto nas missões em Maputo: A prática do turismo e a produção dos lugares: um olhar sobre Macaneta Moçambique, de Edvaldo Cesar Moretti; Olhares do sul de Moçambique por um geógrafo brasileiro, de Angelo Franco do N. Ribeiro; Moçambique e suas particularidades: vivências e olhares, de Amilton Luiz Novaes e Karoline Batista Gonçalves; Memórias de uma experiência de trinta dias em Maputo-Moçambique, de Marisa de Fátima Lomba de Farias; As singularidades do espaço urbano e suas implicações nas práticas territoriais do entorno de Maputo/Moz, de Bruno Ferreira Campos e Cláudia Delboni; Turismo e dinâmicas territoriais: organização e influência das atividades turísticas em Marracuene- Moçambique, de Karoline Batista Gonçalves e Lucas Atanásio Catsossa.

Outro conjunto de três textos, são de colegas que atuaram em Moçambique e durante o projeto realizamos trocas de experiências sobre as vivências em Moçambique e de alguma forma contribuíram para construção de olhares da equipe do projeto sobre Moçambique, foram os textos: leituras geográficas de uma viagem a Maputo, do Douglas Santos; Ukanyi e Gwaza Mutine-festejos culturais e identitários em Maputo e Gaza - Moçambique, de Maria Geralda de Almeida e Constâncio A. Machanguana; Brasil e Moçambique: geopolítica, modernização da agricultura e fome: motes da expansão da fronteira agrícola mundial, de Eguimar Felício Chaveiro, Helsio Amiro Motany de Albuquerque Azevedo, Ernesto Jorge Macaringue e Fernando UhImann Soares.

E contamos com a contribuição de três textos redigidos por colegas Moçambicanos, o texto da professora Inês Raimundo, coordenadora do projeto em Moçambique, O ciclo vicioso de deslocamentos forçados e a formação de espaços incompletos em Moçambique; o texto de Lucas Atanásio Catsossa, A presença brasileira na agricultura moçambicana e os paradigmas do modelo agrário em questão: um olhar 
geográfico sobre o Prosavana; e o artigo do Raimundo Alberto Mulhaisse, Sobreposição territorial: área de conservação total e terras comunitárias na serra da Gorongosa em Moçambique.

Os artigos possuem como unidade relatos e reflexões sobre a geografia de Moçambique, a partir de experiências individuais e coletivas no processo de produção de conhecimento. A leitura dos artigos escancara os desafios impostos no processo de leitura da realidade a partir de experiências vividas, pautada na intensa e complexa troca de saberes e no respeito aos diferentes olhares sobre um lugar prenhe de conflitos e de solidariedade. Boa leitura a todos (as)!

Edvaldo Cesar Moretti

Editor organizador do dossiê da revista Geo UERJ 